\section{Syndecan expressions in the human amnion and chorionic plate}

\author{
T. Lorenzi, ${ }^{1, *}$ A. Turi, ${ }^{2, *}$ C. Crescimanno, ${ }^{3}$ \\ M. Morroni,' M. Castellucci,' G. David, ${ }^{4,5}$ \\ A.L. Tranquilli, ${ }^{2}$ D. Marzioni' \\ 'Department of Molecular Pathology and \\ Innovative Therapies, Anatomy and Cell \\ Biology, Faculty of Medicine, Marche \\ Polytechnic University, Ancona, Italy \\ 2Department of Clinical Sciences, Marche \\ Polytechnic University , Ancona, Italy \\ ${ }^{3}$ Institute of Sciences of Formation, Kore \\ University of Enna, Italy \\ ${ }^{4}$ Department for Molecular and \\ Developmental Genetics, VIB, Leuven, \\ Belgium \\ ${ }^{5}$ Centre for Human Genetics, University \\ of Leuven, Leuven, Belgium \\ *L.T. and T.A. contributed equally to this \\ work as first authors.
}

\section{Abstract}

The syndecan family consists of four distinct membrane glycoproteins in mammals. Syndecans control cell proliferation, differentiation, adhesion and migration through participation in cell-cell interactions, anchorage of cells to the extracellular environment, and modulation of multiple growth factors. Therefore, syndecans may play a pivotal role in the regulation of cell behaviour depending on the cellular microenvironment. Here, we demonstrate that syndecan-1, syndecan-2 and syndecan- 4 are expressed in fetal membrane tissue with different immunolocalizations. Syndecan-1 is expressed in the amniotic epithelium, localizing at basolateral cell surfaces. Syndecan- 2 and syndecan- 4 , in contrast, are mostly localized in intracellular compartments, in the extravillous cytotrophoblastic cells and in some fibroblasts of the chorionic plate as well as in the amniotic epithelial cells. In the latter, syndecan- 4 is mainly localized in the apical part of the cells. Our results strongly suggest a key role of syndecan-1, syndecan-2 and syndecan- 4 in the determination of structural and functional characteristics of human amnion and chorionic plate. Since the solute exchanges between fetus and mother take place in fetal membranes, our data suggest that syndecans are important players in the placenta for the establishment of the fetalmaternal inter-communication.

\section{Introduction}

The fetal membranes (chorioamnion) form a highly specialized interface between mother and fetus, which is necessary for the successful maintenance and termination of pregnancy in higher-level vertebrates.

The chorioamnion forms the outer limits of the sac that encloses the foetus while the innermost layer of the sac is the amniotic membrane (amnion). ${ }^{2}$ The human amnion consists of the amniotic epithelium, a onelayer cluster of polygonal flattened cells with a rectangular to hexagonal top surface, a thick basement membrane and an avascular stroma. ${ }^{3}$ The amniotic epithelium takes part in the regulation of the maternal-fetal exchange and secrets lipid droplets, glycoproteins and proteoglycans at the cell apex. ${ }^{4}$ The amnion is loosely attached to the next layer, the chorionic plate, a tough fibrous tissue layer from the outer surface of which the villous trees originate. The amnion and the chorion provide a large surface area for the potential transfer of both water and low-molecular-mass substances (i.e. glucose, urea) and may play an important role in the regulation of amniotic fluid balance. The intercellular spaces and the extracellular matrix are responsible for the permeability of the fetal membranes that allows diffusion of substrates to occur from mother to fetus, and viceversa. ${ }^{2}$

Syndecans are transmembrane heparan sulfate proteoglycans (HSPGs), which are expressed in a developmentally regulated and tissue-specific manner and play a pivotal role in cell adhesion, migration, proliferation and differentiation. ${ }^{5}$ They act as co-receptors for growth factors, participate in signalling during cell adhesion, modulate the activity of a broad range of molecules, and partake in many developmental and pathological processes, including tumorigenesis and wound repair. ${ }^{6-10}$ In mammals, the syndecan family consists of the products of four distinct syndecan genes. ${ }^{11}$ Syndecan-1 is mainly limited to epithelial cells, but several studies indicate that it is also transiently expressed in mesenchymal cells during embryonic development. ${ }^{12,13}$ Consistent with a role in adhesion, syndecan-1 is present in a basolateral distribution in epithelia, and it appears to regulate epithelial morphology. ${ }^{14}$ Several lines of evidence support the close association between basic fibroblast growth factor (bFGF) function and syndecan-1 expression, syndecan-1 mediating bFGF binding and activity. ${ }^{15}$ Fibroglycan or syndecan-2 is the most abundant syndecan of mesenchymal cells. ${ }^{6,8,16}$ Its expression is developmentally regulated. Expression is low in the early embryonic stage, culminates during morphogenesis and persists in some connective tissue cells of the adult. ${ }^{16}$
Correspondence: Teresa Lorenzi, Ph.D., Department of Molecular Pathology and Innovative Therapies, Anatomy and Cell Biology, Faculty of Medicine, Marche Polytechnic University, via Tronto 10/a, 60020 Ancona, Italy. Tel. +39.071.2206270 - Fax: +39.071.2206087. E-mail: t.lorenzi@univpm.it

Key words: human amnion; chorionic plate; syndecans; cell-cell adhesion; cell-matrix adhesion.

Acknowledgements: the authors wish to thank Dr. Vladia Monsurrò for her help in the first draft of the manuscript and Dr. Pinky Gaidhu for critically reviewing the english form of the manuscript. We gratefully acknowledge the generous support of Fondazione Cassa di Risparmio di Fabriano e Cupramontana. This study was supported by grants from Marche Polytechnic University to A.T., M.M., M.C., A.L.T., D.M.

Contributions: TL, CC, DM, MC substantial contributions to conception and design, acquisition of data, or analysis and interpretation of data; DM, TL, ALT, AT, GD, MM article drafting and critical revision for important intellectual content; TL, DM final approval of the manuscript.

Conflict of interest: the authors report no conflict.

Received for publication: 28 May 2010.

Accepted for publication: 24 August 2010.

This work is licensed under a Creative Commons Attribution 3.0 License (by-nc 3.0).

(C) Copyright T. Lorenzi, et al., 2010

Licensee PAGEPress, Italy

European Journal of Histochemistry 2010; $54: e 42$ doi:10.4081/ejh.2010.e42

Syndecan-2 is highly expressed in fibroblasts and endothelial cells, and is involved in cell adhesion, proliferation, angiogenesis and matrix assembly. ${ }^{17,18}$

Syndecan-3 has essentially been described in brain development. ${ }^{19}$ Consistent with a more limited expression, syndecan-3 is absent in the human placenta. ${ }^{8}$ Amphiglycan or syndecan- 4 is expressed in most tissues, but particularly in liver and kidney, where it localizes on the entire plasma membrane of various types of epithelial and fibroblastic cells..$^{10,20}$ It is mainly involved in cell-matrix attachment, ${ }^{21}$ increasing focal adhesion formation and decreasing cell motility. ${ }^{22}$

Given that the amnion and chorionic plate play a key role in the inter-communication between fetus and mother and considering the multi-faceted role of syndecans in cell-cell and cell-matrix interactions, we analyzed syndecan expressions by immunohistochemistry in the chorionic plate and amniotic epithelium. We show here, for the first time, that syndecan-1, syndecan- 2 and syndecan- 4 are expressed in human fetal membranes with different immunolocalizations. 


\section{Materials and Methods}

\section{Tissue preparation}

Fourteen human placentas aged $38(\mathrm{n}=6)$ and $40(n=8)$ weeks of gestation were collected from clinically normal pregnancies terminated by cesarean sections. One to four specimens were excised from each placenta. The study was approved by the Regional Ethics Committee and informed consent was obtained from all patients.

Each specimen included the full thickness of the placenta i.e. from the chorionic to the basal plate. Specimens were fixed overnight in 4\% neutral buffered formalin at $4^{\circ} \mathrm{C}$, then routinely processed for paraffin embedding at $56^{\circ} \mathrm{C}$, as previously described. ${ }^{23}$ Paraffin sections ( $3 \mu \mathrm{m})$ were cut and stretched at $45^{\circ} \mathrm{C}$, allowed to dry and stored at $4^{\circ} \mathrm{C}$ until use.

\section{Immunohistochemistry}

Immunohistochemistry for syndecans (1-4) was performed as previously described. ${ }^{8}$ Briefly, paraffin sections were deparaffinated and rehydrated via xylene and a graded series of ethyl alcohol. Sections were rinsed in PBS and incubated with $3 \% \mathrm{H}_{2} \mathrm{O}_{2}$ in methanol for 30 min to inhibit endogenous peroxidase activity. Non-specific antibody binding was blocked with $3 \%$ BSA in PBS for 30 min. Afterwards, the sections were incubated for $45 \mathrm{~min}$ at room temperature with one of the monoclonal primary antibodies (Table 1). After washing in three changes of PBS, the sections were subsequently incubated with biotinylated antimouse antibody (Vector Laboratories, Burlingame, CA, USA). The peroxidase ABC method (Vector Laboratories) was performed for $1 \mathrm{~h}$ at room temperature, using 3',3' diaminobenzidine hydrochloride (Sigma, St Louis, MO, USA) as chromogen.

Sections were counterstained in Mayer's haematoxylin, rinsed with distilled water, dehydrated and mounted with Eukitt solution (Kindler GmbH and Co., Freiburg, Germany). Negative controls were implemented by replacing the primary antibody with PBS. Further controls were performed by omitting the secondary antibody and using an isotype control antibody. The negative controls confirmed the specificity of the immunolabeling obtained with the primary antibodies. Normal bladder tissue was used as positive control for syndecan-3. ${ }^{10}$

\section{Results}

The immunolabeling of each syndecan has similar localization and intensity in all fourteen human placentas. The amniotic epithelial
Table 1. Antibodies used in this study.

\begin{tabular}{cccc} 
Antibodies & Specificity & Ab conc & Reference \\
mAb B-B4 & $\begin{array}{c}\text { Syndecan-1 } \\
\text { (ectodomain) }\end{array}$ & $1: 60(\mathrm{v} / \mathrm{v})$ & Serotec, Oxford, UK \\
mAb 10H4 & $\begin{array}{c}\text { Syndecan-2 } \\
\text { (ectodomain) }\end{array}$ & $20-30 \mu \mathrm{g} / \mathrm{mL}$ & Lories et al., $1989^{35}$ \\
\hline $\mathrm{mAb} \mathrm{1C7}$ & $\begin{array}{c}\text { Syndecan-3 } \\
\text { (ectodomain) }\end{array}$ & $2-3 \mu \mathrm{g} / \mathrm{mL}$ & Lories et al., $1989^{35}$ \\
mAb 8G3 & $\begin{array}{c}\text { Syndecan-4 } \\
\text { (ectodomain) }\end{array}$ & $50-100 \mu \mathrm{g} / \mathrm{mL}$ & Lories et al., $1989^{35}$ \\
& & &
\end{tabular}

mAb, monoclonal antibody.

cells were immunolabeled for syndecan-1 at their basolateral surface (Figure $1 \mathrm{a}, \mathrm{b}$ ). The extravillous cytotrophoblastic cells underlying chorionic mesoderm as well as connective tissue cells of the chorionic plate were negative for syndecan-1. A strong staining pattern for syndecan-2 was localized in the cytoplasm of the amniotic epithelium, in the extravillous cytotrophoblastic cells and in some connective fibroblast cells of the chorionic plate (Figure 1 c). Syndecan-3 was not detectable, neither in the chorionic plate, nor in the amniotic epithelium. On the contrary, the extravillous cytotrophoblastic cells, some fibroblasts of the connective tissue and the amniotic epithelial cells were immunoreactive for syndecan-4 (Figure 1 d,e). The immunostaining was mainly intracellular, however in amniotic epithelial cells an intense immunoreactivity was localized at the apical part of the cells (Figure $1 \mathrm{~d}, \mathrm{e}$ ).

\section{Discussion}

Syndecans function as co-receptors, modulating the activity of primary receptors at the cell surface, by binding a variety of growth factors and extracellular matrix components via covalently linked heparan sulfate chains present in their ectodomain. Through these interactions, syndecans play various roles in cellmatrix and cell-cell adhesion, migration, and proliferation. The binding of cells to the extracellular matrix molecules via syndecans and matrix receptors may regulate cell morphology and influence cell behaviour through the interaction of ligated receptors and co-receptors with cytoplasmic molecules. In fact, this interaction allows the signal transduction through the plasma membrane, resulting in intracellular changes and alterations in gene expression that lead to the regulation of cell differentiation. ${ }^{24}$ Because alterations in syndecan expressions enable cells to become more or less responsive to their micro-environment and considering the important exchange processes that take place between the amniotic fluid and the maternal compartment, the aim of our study was to analyze the expression of synde-

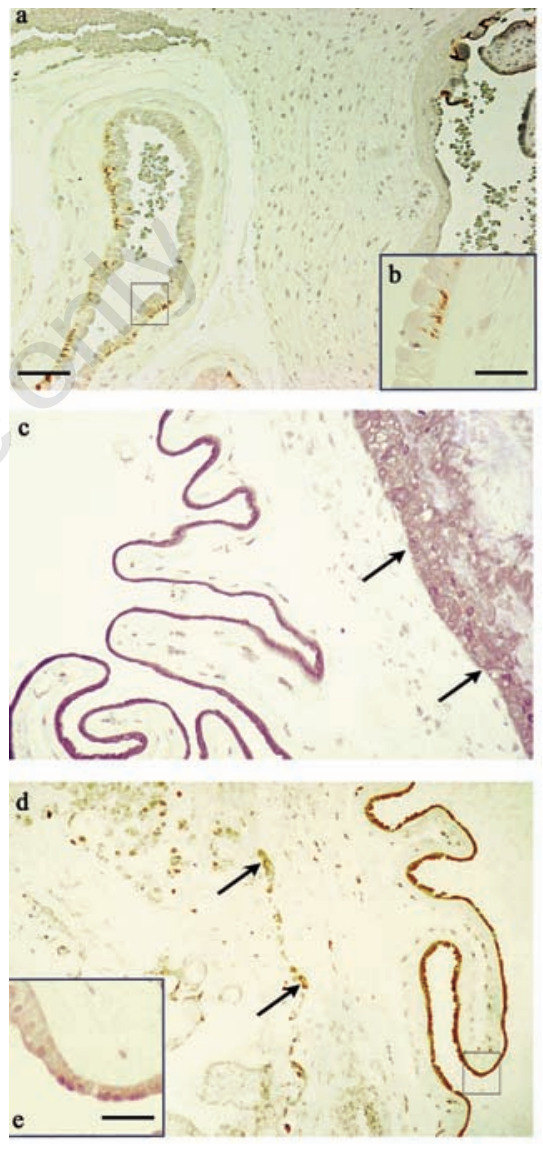

Figure 1. Paraffin sections of term placentas. (a) Immunohistochemical localization of syndecan-1 using the antibody B-B4. (b) Shows a high magnification of the squared area depicted in panel a. Cellular plasmamembrane of amniotic epithelium shows an evident immunostaining in the basolateral compartment. (c) Immunostaining for syndecan-2 with the antibody $10 \mathrm{H} 4$. The amniotic epithelium and the trophoblast (arrows) underneath the amnion are positive in the cytoplasm. (d). Immunoreactivity of syndecan -4 revealed by the antibody 8G3. Arrows indicate immunostained extravillous cytotrophoblastic cells. (e) Shows a high magnification of the squared area depicted in panel (d) The staining is localized in the intracellular compartment of amniotic epithelium but it is more intense at the apex of the epithelial cells.

a,c,d: Bar=90 $\mu \mathrm{m}$; b,e: $\operatorname{Bar}=25 \mu \mathrm{m}$. 
cans in amniotic epithelium and chorionic plate of human placenta.

Our results indicate that syndecan-3 is not detectable, according with previous data that demonstrate the absence of this molecule in human placenta. ${ }^{8}$ Instead, syndecan- 2 and syndecan-4 were primarily localized in the intracellular compartment, whereas syndecan-1 was expressed on the plasma membrane. The differential localization of syndecans may reflect different roles of these molecules within amniotic epithelium and chorionic plate. Syndecans may be involved in maintaining the morphology and the organization of the cells through their interactions with the cytoskeleton. This is supported by evidence that transmembrane and cytoplasmic domains of syndecans can associate with and reorganize cytoskeletal actin, resulting in changes in cellular shape and structure. ${ }^{25}$ Interestingly, syndecan-2 and syndecan- 4 were mostly localized inside cells, both in the amniotic epithelium and in the extravillous cytotrophoblastic cells of the chorionic plate. This localization may have a structural function, suggesting a potential contribution of syndecan- 2 and syndecan- 4 to the tensile strength of fetal membranes, thereby supporting the resistance of placenta against over-distension.

Syndecan- 2 and syndecan- 4 are transmembrane proteoglycans that support integrinmediated cell-matrix and cell-cell adhesion. ${ }^{7}$ Both syndecan- 2 and syndecan- 4 are particularly abundant in sites where several cell-cell and cell-matrix interactions are known to occur. $^{4}$ In this context, these two syndecans may also regulate both the active transport of solute by the amnion into the amniotic space and passive water diffusion, directly or by modifying cell-cell and cell-matrix contacts. The cell-matrix adhesion is also regulated by the formation of focal adhesions, macromolecular structures through which the cell attaches to the extracellular matrix. ${ }^{26}$ In addition, many cellular responses to ligands are also stimulated by the formation of focal adhesions. ${ }^{27}$ Studies have revealed that syndecan-4 is a focal adhesion component which may both localize protein kinase $\mathrm{C}$ and amplify its activity at sites of adhesion formation. ${ }^{28,29}$ Therefore, the syndecan- 4 localization at the apex of amniotic epithelial cells could underline a crucial role of this molecule in the sensing of amniotic fluid environment.

In contrast, syndecan-1 was detected at the basolateral plama membrane of the amniotic epithelial cells, however was absent in the extravillous cytotrophoblastic cells and connective tissue cells of the chorionic plate. This immunolocalization is compatible with the fact that syndecan-1 is expressed predominantly in epithelial cells and uniquely restricted to the basolateral surface. This would promote cell- cell adhesion, maintaining the epithelial phenotype and organization. ${ }^{30-33}$ Down-regulation of syndecan-1 causes epithelial cells to lose their cuboidal morphology, migrate and grow independent of anchorage. ${ }^{32}$ It is intriguing that syndecan-1 shows a different cellular localization depending on the placenta compartments. In fact, the syncytiotrophoblast of human chorionic villi expresses syndecan-1 on the apical surface and not in the basolateral one. ${ }^{8}$ This peculiar staining pattern likely reflects the role of syndecan- 1 in the active communication between fetal villi and maternal blood. Syndecan-1 acts as co-receptor for bFGF allowing the binding of the growth factor to its signalling receptor on the plasma membrane. ${ }^{34}$ Syndecan- 1 clearly plays a part in regulating the signal transduction pathways that transmit the extracellular signal of bFGF into the nucleus. Previous studies suggest that certain substances could be transported toward the amnion from the underlying trophoblast layer of the fetal membranes and chorionic plate. $^{3}$ In amniotic epithelium, the potential basolateral bFGF signal coming from the underlying layers ${ }^{23}$ probably takes place in order to permit the amnion extension during placenta development. On the other hand, in the syncytiotrophoblast, the apical bFGF signalling from mother is likely required for the growth of the fetal villous tree.

In conclusion, this is the first report that analyses the expression of syndecans in human fetal membranes. Our results strongly suggest a key role of syndecan-1, syndecan-2 and syndecan- 4 in the determination of structural and functional characteristics of human amnion and chorionic plate.

These new data are useful to improve the understanding of the basic components of human fetal membranes, in order to shed light on both the normal biology and pathobiology of these tissues, which is crucial for the eventual control of some pregnancy complication as preterm labor.

\section{References}

1. Calvin SE, Oyen ML. Microstructure and mechanics of the chorioamnion membrane with an emphasis on fracture properties. Ann N Y Acad Sci 2007;1101:166-85.

2. Garby L. Studies on transfer of matter across membranes with special reference to the isolated human amniotic membrane and the exchange of amniotic fluid. Acta Physiol Scand Suppl 1957;40:1-84.

3. Schmidt W. The amniotic fluid compartment: the fetal habitat. Adv Anat Embryol Cell Biol 1992;127:1-100.

4. Benirschke K, Kaufmann P, Baergen RN.
Pathology of the Human Placenta. 5th ed. 2006, Springer-Verlag, New York, USA.

5. Bernfield M, Götte M, Park PW, Reizes 0, Fitzgerald ML, Lincecum J et al. Functions of cell surface heparan sulfate proteoglycans. Annu Rev Biochem 1999;68:729-77.

6. Couchman JR, Woods A. Syndecans, signalling, and cell adhesion. J Cell Biochem 1996;61:578-84.

7. Woods A, Couchman JR. Syndecans: synergistic activators of cell adhesion. Trends Cell Biol 1998;8:189-92.

8. Crescimanno C, Marzioni D, Paradinas FJ, Schrurs B, Mühlhauser J, Todros T et al. Expression pattern alterations of syndecans and glypican-1 in normal and pathological trophoblast. J Pathol 1999;189:60008.

9. Tumova S, Woods A, Couchman JR. Heparan sulfate proteoglycans on the cell surface: versatile coordinators of cellular functions. Int J Biochem Cell Biol 2000; 32:269-88.

10. Marzioni D, Lorenzi T, Mazzucchelli R, Capparuccia L, Morroni M, Fiorini R, et al. Expression of basic fibroblast growth factor, its receptors and syndecans in bladder cancer. Int J Immunopathol Pharmacol 2009;22:627-38.

11. Bernfield M, Hinkes MT, Gallo RL. Developmental expression of the syndecans: possible function and regulation. Dev Suppl 1993:205-12.

12. Thesleff I, Jalkanen M, Vainio S, Bernfield M. Cell surface proteoglycan expression correlates with epithelial-mesenchymal interaction during tooth morphogenesis. Dev Biol 1988;129:565-72.

13. Solursh M, Reiter RS, Jensen KL, Kato M, Bernfield M. Transient expression of a cell surface heparan sulfate proteoglycan (syndecan) during limb development. Dev Biol 1990;140:83-92.

14. Couchman JR, Chen L, Woods A. Syndecans and cell adhesion. Int Rev Cytol 2001;207:113-50.

15. Filla MS, Dam P, Rapraeger AC. The cell surface proteoglycan syndecan-1 mediates fibroblast growth factor-2 binding and activity. J Cell Physiol 1998;174:310-21.

16. David G, Bai XM, Van der Schueren B, Marynen P, Cassiman JJ, Van den Berghe H. Spatial and temporal changes in the expression of fibroglycan (syndecan-2) during mouse embryonic development. Development 1993;119:841-54.

17. Couchman JR. Syndecans: proteoglycan regulators of cell-surface microdomains? Nat Rev Mol Cell Biol 2003;4:926-37.

18. Fears CY, Gladson CL, Woods A. Syndecan2 is expressed in the microvasculature of gliomas and regulates angiogenic processes in microvascular endothelial cells. $\mathrm{J}$ 
Biol Chem 2006;28:14533-6.

19. Fears CY, Woods A. The role of syndecans in disease and wound healing. Matrix Biol 2006;25:443-56.

20. David G, van der Schueren B, Marynen P, Cassiman JJ, Van den Berghe H. Molecular cloning of amphiglycan, a novel integral membrane heparan sulfate proteoglycan expressed by epithelial and fibroblastic cells. J Cell Biol 1992;118:961-9.

21. Greene DK, Tumova S, Couchman JR, Woods A. Syndecan-4 associates with alpha-actinin. J Biol Chem 2003;278:761723.

22. Longley RL, Woods A, Fleetwood A, Cowling GJ, Gallagher JT, Couchman JR. Control of morphology, cytoskeleton and migration by syndecan-4. J Cell Sci 1999;112:3421-31.

23. Mühlhauser J, Marzioni D, Morroni M, Vuckovic M, Crescimanno C, Castellucci M. Codistribution of basic fibroblast growth factor and heparan sulfate proteoglycan in the growth zones of the human placenta. Cell Tissue Res 1996;285:101-7.

24. Leppä S, Mali M, Miettinen HM, Jalkanen M. Syndecan expression regulates cell morphology and growth of mouse mammary epithelial tumor cells. Proc Natl Acad Sci
USA 1992;89:932-6.

25. Yoneda A, Couchman JR. Regulation of cytoskeletal organization by syndecan transmembrane proteoglycans. Matrix Biol 2003;22:25-33.

26. Chen CS, Alonso JL, Ostuni E, Whitesides GM, Ingber DE. Cell shape provides global control of focal adhesion assembly. Biochem Biophys Res Commun 2003;307:355-61.

27. Horowitz A, Tkachenko E, Simons M. Fibroblast growth factor-specific modulation of cellular response by syndecan-4. J Cell Biol 2002;157:715-25.

28. Oh ES, Woods A, Couchman JR. Multimerization of the cytoplasmic domain of syndecan-4 is required for its ability to activate protein kinase C. J Biol Chem 1997;272:11805-11.

29. Oh ES, Woods A, Couchman JR. Syndecan4 proteoglycan regulates the distribution and activity of protein kinase C. J Biol Chem 1997;272:8133-6.

30. Stanley MJ, Liebersbach BF, Liu W, Anhalt DJ, Sanderson RD. Heparan sulfate-mediated cell aggregation. Syndecans- 1 and -4 mediate intercellular adhesion following their transfection into human B lymphoid cells. J Biol Chem 1995;270:5077-83.

31. Inki P, Stenbäck F, Grenman S, Jalkanen M. Immunohistochemical localization of syndecan-1 in normal and pathological human uterine cervix. J Pathol 1994;172:349-55.

32. Kato M, Saunders S, Nguyen H, Bernfield M. Loss of cell surface syndecan-1 causes epithelia to transform into anchorageindependent mesenchyme-like cells. Mol Biol Cell 1995;6:559-76.

33. Cohen AR, Woods DF, Marfatia SM, Walther Z, Chishti AH, Anderson JM. Human CASK/LIN-2 binds syndecan-2 and protein 4.1 and localizes to the basolateral membrane of epithelial cells. J Cell Biol 1998;142:129-38.

34. Larraín J, Cizmeci-Smith G, Troncoso V, Stahl RC, Carey DJ, Brandan E. Syndecan1 expression is down-regulated during myoblast terminal differentiation. Modulation by growth factors and retinoic acid. J Biol Chem 1997;272:18418-24.

35. Lories V, Cassiman JJ, Van den Berghe H, David G. Multiple distinct membrane heparan sulfate proteoglycans in human lung fibroblasts. J Biol Chem 1989;264: 7009-16. 